\title{
PERENCANAAN IN PIT DUMP (IPD) PIT D2 UNTUK OPPORTUNITY REDUCE DISTANCE DAN MITIGASI DARI BAHAYA GEOTEKNIK BLOK 1-4, BINUNGAN MINE OPERATION 1 - PT. BERAU COAL
}

\author{
Muhammad Endriantho' ${ }^{1)}$, Pandu Zea Ardiansyah ${ }^{2)}$, Alex Prabudi ${ }^{3)}$ \\ ${ }^{1)}$ Short Term Mine Planning, PT. Berau Coal \\ ${ }^{2)}$ Geotechnical Engineer, PT Berau Coal \\ ${ }^{3)}$ Short Term Departement Head, PT Berau Coal
}

\begin{abstract}
ABSTRAK
Pit D2 merupakan salah satu Pit dengan metode tambang terbuka di PT. Berau Coal yang berlokasi di Binungan Mine Operation-1. Pit D2 di kerjakan oleh PT. Sapta Indra Sejati (PT. SIS) sebagai mitra kerja dari PT Berau Coal. Target produksi tahun 2019 Pit D2 yaitu overburden 16.117.353 BCM, Coal 1.473.686 MT dengan SR 9,59. Pit D2 berada disisi selatan sungai Kelay dan merupakan akses utama jalan hauling coal BMO1 dan transportasi karyawan dari Rumah / mess ke site Tambang BMO1 dan BMO2.

Secara LOM, Plan Disposal terdapat pada Out Pit Dump (OPD) D2 dengan kapasitas disposal 30 MBCM pada jarak 2,6 Km dan In Pit Dump $K$ dengan kapasitas disposal 6 MBCM pada jarak 3,2 Km. In Pit Dump K harus dilakukan karena merupakan disposal material rawa Pit D2 tahun 2019 sebanyak 6 MBCM. Salah satu opportunity untuk menurunkan angka distance adalah dengan melakukan In Pit Dump Pit D2 dengan percepatan finishing pit sehingga didapatkan distance 1,8 Km dengan kapasitas 5 MBCM. Kapasitas volume In Pit Dump terbatas dikarenakan perlu kajian geoteknik sehingga disposal In Pit Dump aman dikerjakan. Adapun overall distance 2019 adalah $2,4 \mathrm{~km}$.

Secara geoteknik, Pit D2 terdapat struktur geologi kompleks membentuk lembah lipatan (syncline) dan punggung lipatan (anticline) dengan batuan yang bersifat low strength. Adapun seam utama (main seam) batubara yaitu D-2, litologi area Pit D2 memiliki kemiringan perlapisan (dip) 6-10. Hasil cross section pada desain rencana Pit dengan litologi batuan memperlihatkan adanya potensi bedding undercut di sisi side wall utara. Historical longsor di side wall telah terjadi sebanyak 2 kali dalam waktu 1 Tahun, hasil analisis geoteknik secara LOM desain terjadinya longsoran dikarenakan desain yang membentuk bedding undercut dengan bidang gelincir dibawah seam D-2 yang menyebabkan terjadinya longsoran bidang, ditambah banyaknya joint vertical yang membuat terjadinya longoran toppling. PT. Berau Coal tidak memperbolehkan adanya pemotongan bedding undercut dan masuk dalam 11 Golden Rules PT Berau Coal. Untuk melakukan bedding under cut diperlukan kajian geoteknik untuk analisisnya.

Adanya opportunity short distance dan perencanaan mitigasi bahaya geoteknik maka Mine Planner dan Geotechnic Engineer membuat perencanaan In Pit Dump Pit D2 secara paralel dengan kemajuan tambang, sehingga dari segi perencanaan dibutuhkan timing dan sequence yang tepat untuk mengeksekusi area sidewall utara.
\end{abstract}

Kata Kunci: Reduce Distance, Bedding Undercut, In Pit Dump, Geotechnical Mitigation

\section{A. PENDAHULUAN}

\section{A.1 Latar Belakang}

Pit D2 merupakan salah satu Pit dengan metode Tambang Terbuka di PT. Berau Coal yang berlokasi di Binungan Mine Operation-1. Pit D2 di kerjakan oleh PT. Sapta Indra Sejati (PT. SIS) sebagai mitra kerja dari PT Berau Coal. Target produksi tahun 2019 Pit D2 yaitu overburden (lapisan batuan penutup)16.117.353 BCM dan batubara 1.473.686 MT dengan Striping Ratio (perbandingan overburden dengan coal) 9,59. Pit D2 berada disisi selatan sungai Kelay dan 
merupakan akses utama jalan hauling coal BMO1 dan transportasi karyawan dari rumah / mess ke site (lokasi) tambang BMO1 dan BMO2.

Secara life of mine (umur penambangan), rencana penempatan material overburden (disposal) terdapat pada Out Pit Dump (OPD) D2 dengan kapasitas disposal $30 \mathrm{MBCM}$ pada jarak $2.6 \mathrm{Km}$ dan In Pit Dump (IPD) $K$ dengan kapasitas disposal $6 \mathrm{MBCM}$ pada jarak $3.2 \mathrm{Km}$. In Pit Dump K harus dilakukan karena merupakan disposal material rawa Pit D2 tahun 2019 sebanyak 6 MBCM. Salah satu opportunity untuk menurunkan angka distance adalah dengan melakukan In Pit Dump Pit D2 dengan percepatan finishing pit sehingga didapatkan distance 1,8 $\mathrm{Km}$ dengan kapasitas 5 MBCM. Kapasitas volume In Pit Dump terbatas dikarenakan perlu kajian Geoteknik sehingga disposal In Pit Dump aman dikerjakan. Adapun overall distance (total jarak angkut keseluruhan) 2019 adalah $2.4 \mathrm{Km}$.

Secara geoteknik, Pit D2 terdapat struktur geologi kompleks membentuk lembah lipatan (syncline) dan punggung lipatan (anticline) dengan batuan yang bersifat low strength. Adapun lapisan utama (main seam) batubara yaitu D-2, litologi area Pit D2 memiliki kemiringan perlapisan (dip) 6-10'. Hasil cross section pada desain rencana Pit dengan litologi batuan memperlihatkan adanya potensi bedding undercut (potong perlapisan batuan) di sisi sidewall utara. Historical longsor di sidewall telah terjadi sebanyak 2 kali dalam waktu 1 tahun, hasil analisis geoteknik secara LOM desain terjadinya longsoran dikarenakan desain yang membentuk bedding undercut dengan bidang gelincir dibawah seam D-2 yang menyebabkan terjadinya longsoran bidang, ditambah banyaknya joint vertical yang membuat terjadinya longoran toppling. PT. Berau Coal tidak memperbolehkan adanya pemotongan bedding undercut dan masuk dalam 11 Golden Rules PT Berau Coal. Untuk melakukan bedding undercut diperlukan kajian geoteknik untuk analisisnya.

Longsoran baji beberapa kali terjadi di Pit ini pada lokasi yang berbeda-beda. Rekahan terbesar yang pernah dijumpai adalah rekahan pada highwall. Rekahan ini memiliki offset penurunan hingga 1,5 m. Panjang busur rekahan mencapai $180 \mathrm{~m}$ dengan jarak busur terluar terhadap crest highwall mencapai $40 \mathrm{~m}$. Pada sisi selatan Pit D2, dijumpai perlipatan lapisan batuan. Perlipatan ini memutar kemiringan lapisan batuan hingga 90 derajat. Selain perlipatan, area lowwall juga dijumpai offset mineout. Besaran offset tersebut berkisar antara $30-50 \mathrm{~cm}$.

\section{A.2 Tujuan}

Tujuan yang diharapkan dari penelitian ini adalah adanya short distance (jarak angkut lebih pendek) dan perencanaan mitigasi bahaya geoteknik dengan membuat perencanaan In Pit Dump Pit D2 secara paralel dengan kemajuan tambang. Hal ini dapat membuat opportunity keuntungan bagi PT Berau Coal dengan mengurangi distance (jarak angkut) dan tetap melaksanakan good mining practice pada penambangan Pit D2.

\section{A.3 Pendekatan pemecahan masalah}

Rencana penambangan Pit D2 tahun 2019 akan mempunyai 3 opsi disposal yaitu, OPD D2, IPD K, dan IPD D2. Keadaan tambang komoditas batubara yang sedang mengalami penurunan membuat mine planning dan geotechnical engineer PT Berau Coal harus membuat inovasi agar dapat memecahkan permasalahan yaitu jarak hauling atau kebutuhan akan short distance (jarak angkut dekat). Jarak disposal OPD D2 dan IPD K cukup jauh sehingga akan dibuatkan simulasi short distance pada IPD D2 untuk balancing distance (menyeimbangkan jarak angkut jauh) tahun 2019 pada target distance $2,4 \mathrm{Km}$. Adanya issue geoteknik di sisi utara yang cukup berisiko sehingga dilakukan kajian geoteknik terhadap desain Pit dan Disposal IPD D2 sebagai mitigasi dari bahaya geoteknik. Hasil analisis geoteknik diketahui Pit D2 pada area bedding undercut (potong perlapisan) dapat dikerjakan dengan pembentukan single slope (kemiringan satu jenjang) $30^{\circ}$ dan overall slope (kemiringan secara keseluruhan) $\leq 15^{\circ}$ sehingga didapatkan FK 1,3 


\section{B. METODOLOGI PENELITIAN}

Penelitian dilakukan dengan pembuatan desain Disposal IPD D2 sesuai dengan kemajuan tambang. Diperlukan kapasitas Disposal 5 MBCM untuk mendapatkan overall distance 2019 dibawah 2,4 $\mathrm{km}$. Adapun Disposal IPD D2 harus dikaji secara geoteknik dengan faktor keamanan (FK) yang sudah ditetapkan oleh PT Berau Coal yaitu $\geq 1,3$ dengan overall slope $\leq 15^{\circ}$.

\section{HASIL DAN PEMBAHASAN}

\section{C.I Desain Disposal IPD D2}

Simulasi balancing distance Pit D2 dengan pertimbangan kapasitas IPD K dan OPD D2 maka dibutuhkan kapasitas IPD D2 minimal 5 MBCM. Rencana operasional penambangan akan berjalan 6 fleet (1 fleet merupakan satu operasional penambangan yang terdiri dari alat muat dan alat angkut). Pada IPD $\mathrm{K}$ hanya mempunyai kapasitas $5 \mathrm{MBCM}$ untuk dumping material rawa sehingga maksimal hanya 2 fleet yang beroperasi dengan 1 fleet material blasting untuk blending (pencampuran) material rawa di disposal. Selain itu distance yang cukup jauh $(3,2 \mathrm{Km})$ tidak memungkinkan untuk menambah fleet yang beroperasi. Pada OPD D2 mempunyai kapasitas disposal diatas 30 MBCM sehingga dapat menampung semua material overburden dari Pit D2, akan tetapi distance ke OPD D2 juga cukup jauh $(2,6 \mathrm{~km})$. Sehingga akan dibuatkan desain IPD D2 yang maksimal sesuai dengan kajian geoteknik dan kemajuan tambang.

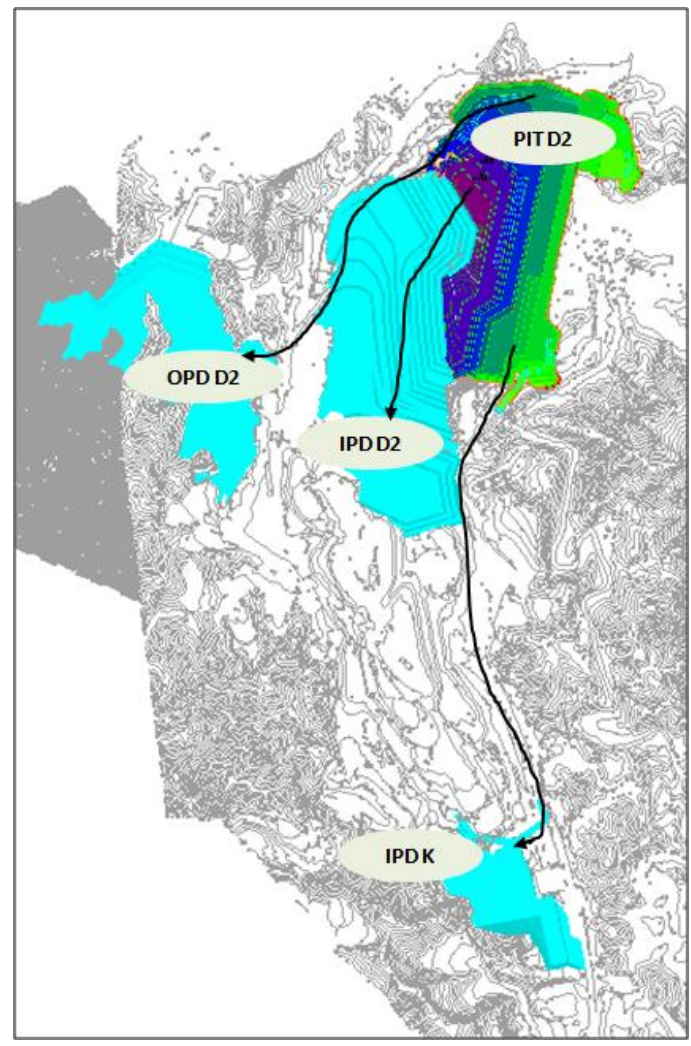

Gambar 1. Peta Rencana Disposal Pit D2 Tahun 2019

Simulasi running distance dilakukan dengan software xpac untuk melihat skenario distance yang diinginkan. Run scenario (simulasi skenario) dilakukan dengan mengatur jarak kaki disposal IPD D2 dengan kemajuan tambang (Pit finish) sehingga akan terlihat kapasitas IPD D2 setiap bulannya. 


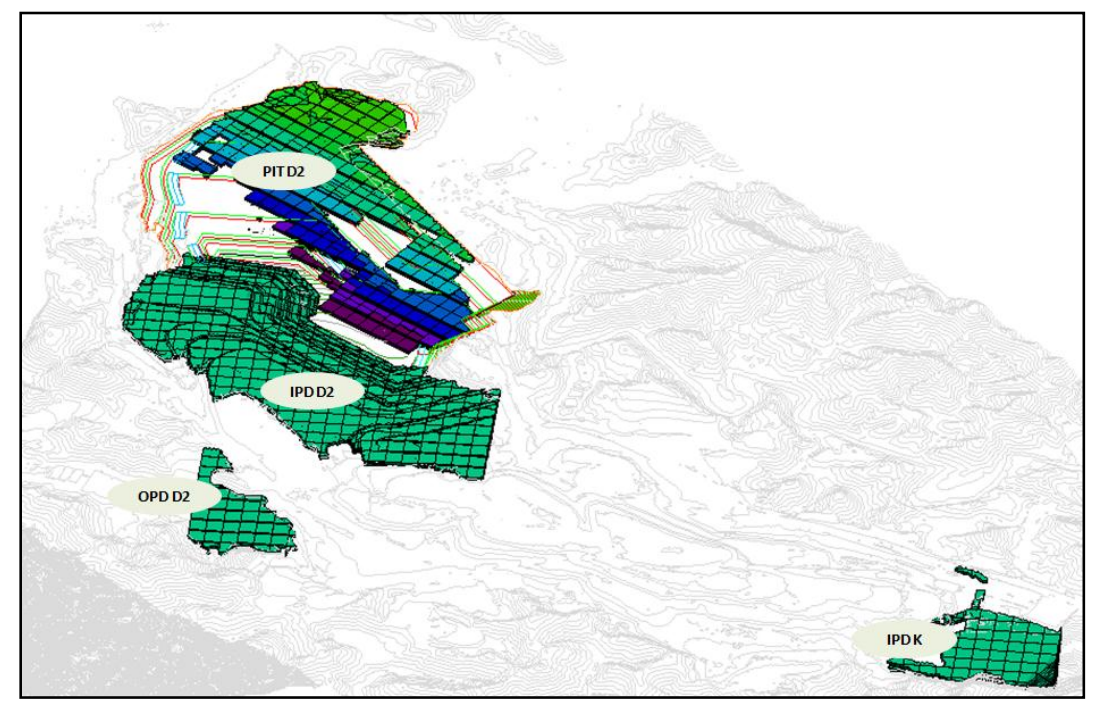

Gambar 2. Simulasi Disposal Pit D2 Akhir Tahun 2019

Simulasi run scenario OB removal (pemindahan material) dan distance dilakukan setiap bulan untuk mendapatkan gambaran distance.

Tabel 1. Simulasi Dump dan Distance Report menggunakan Software Xpac

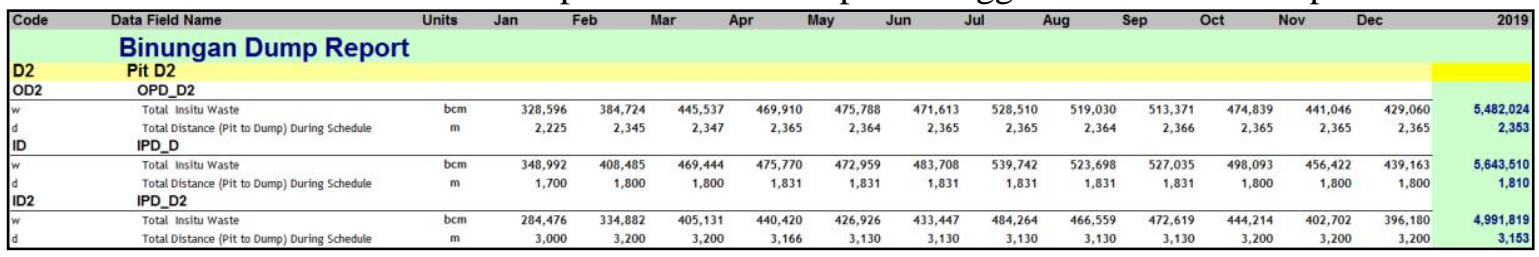

\section{C.2 Kajian Geoteknik Disposal IPD D2}

\section{C.2.1 Lokasi Rencana Disposal IPD D2}

Desain yang sudah dibuat dilakukan analisi geoteknik untuk mengetahui faktor keamanan sebagai syarat dilakukannya operasional dumping.

(a)

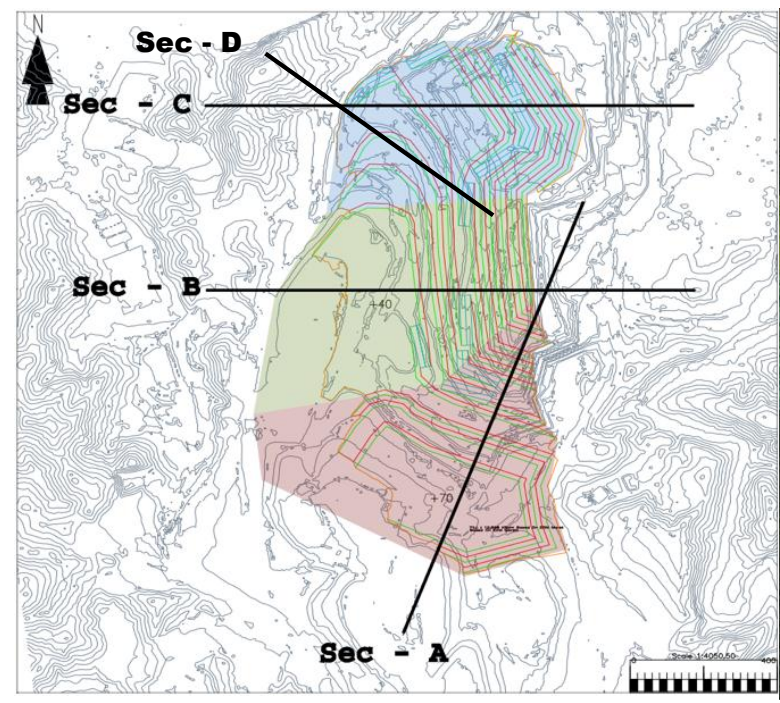

(b)

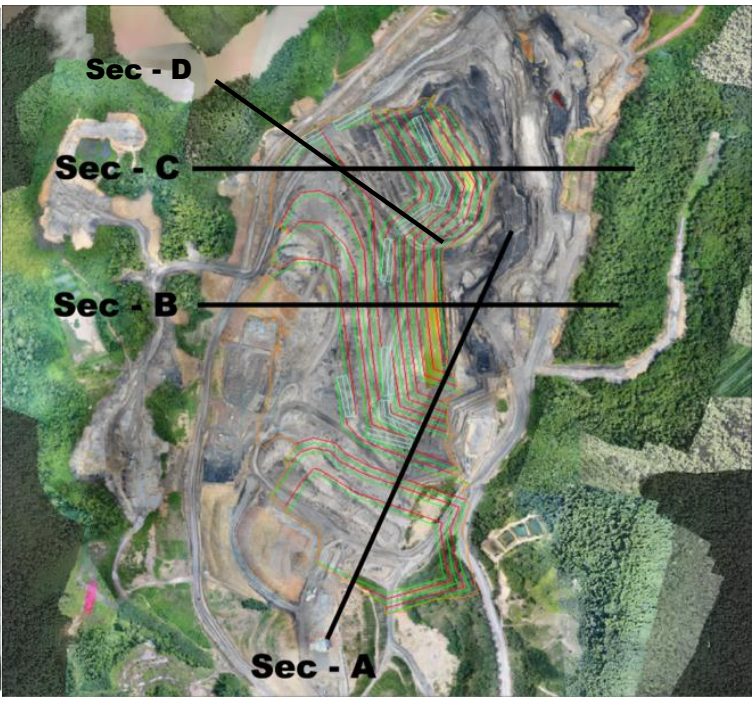

Gambar 3. (a) Peta dan (b) Ortho Photo Section IPD D2 


\section{C.2.2 Analisis Geoteknik Disposal IPD D2}

Analisis geoteknik yang dilakukan pada disposal IPD D2 merupakan analisis kestabilan lereng dengan metode kesetimbangan batas.

Dalam analisis metode kesetimbangan batas dilakukan pendekatan sebagai berikut:

1. Perhitungan dan analisis menggunakan software slide dari rocksience dengan metode keruntuhan circular untuk highwall / sidewall / rawa / timbunan jalan dan non-circular untuk lereng lowwall

2. Data yang digunakan dalam analisis

a) Desain yang digunakan :

Ipdd2_2019_r3_1.dgn, week_w1719_b14.dgn, dan bmo_1904_14.dgn.

b) Data rawa (rawa_bin14_upd.dgn) dan litologi batuan diperoleh dari G\&E Dept.

c) Beban blasting adalah 0,03 g dan analisis dilakukan dalamkondisi fully saturated.

3. Desain dinyatakan aman jika memiliki faktor keamanan $\mathrm{FK} \geq 1,30$ untuk lereng original dan timbunan serta $\mathrm{FK} \geq 1,50$ untuk infrastruktur.

Tabel 2. Parameter Material Analisis

\begin{tabular}{ccccccc}
\hline Material & $\begin{array}{c}\text { Unit Weight } \\
\left(\mathbf{k N} / \mathbf{m}^{3}\right)\end{array}$ & $\begin{array}{c}\text { Cohesion } \\
(\mathbf{k P a})\end{array}$ & $\begin{array}{c}\text { Int Friction } \\
\left.\text { Angle } \mathbf{(}^{(}\right)\end{array}$ & $\begin{array}{c}\text { UCS } \\
\left(\mathbf{k N} / \mathbf{m}^{2}\right)\end{array}$ & GSI & $\begin{array}{c}\text { Intact Rock } \\
(\mathbf{m i})\end{array}$ \\
\hline Soil & 16 & 40 & Undrained & & & \\
Sandstone & 22.1 & 155.8 & 31.23 & & & \\
Mudstone & 21.5 & 146.75 & 30.32 & & & \\
Existing Fill & 19.5 & 68 & 22 & & & \\
New Fill & 19 & 68 & 17 & & & \\
Material & 17 & 25 & Undrained & & & \\
Lunak/Rawa & 20 & 135 & 35 & & & \\
Coal & 20 & & & 1400 & 45 & 9 \\
Bedding & & & & & & \\
\hline
\end{tabular}

\section{C.2.3 Hasil Analisis Geoteknik Disposal IPD D2}

- Analisis Bedding Undercut Lowwall Pit D2

Pada Section - D pada peta desain diatas merupakan section dimana desain lowwall melakukan pemotongan undercut yang membuat kestabilan lereng original menjadi tidak stabil, dibutuhkan pencegahan dengan timing yang tepat agar longsoran tidak terjadi, dimana dari hasil runningan analisis geoteknik FK desain undercut $<$ 1,3 (gambar.4)

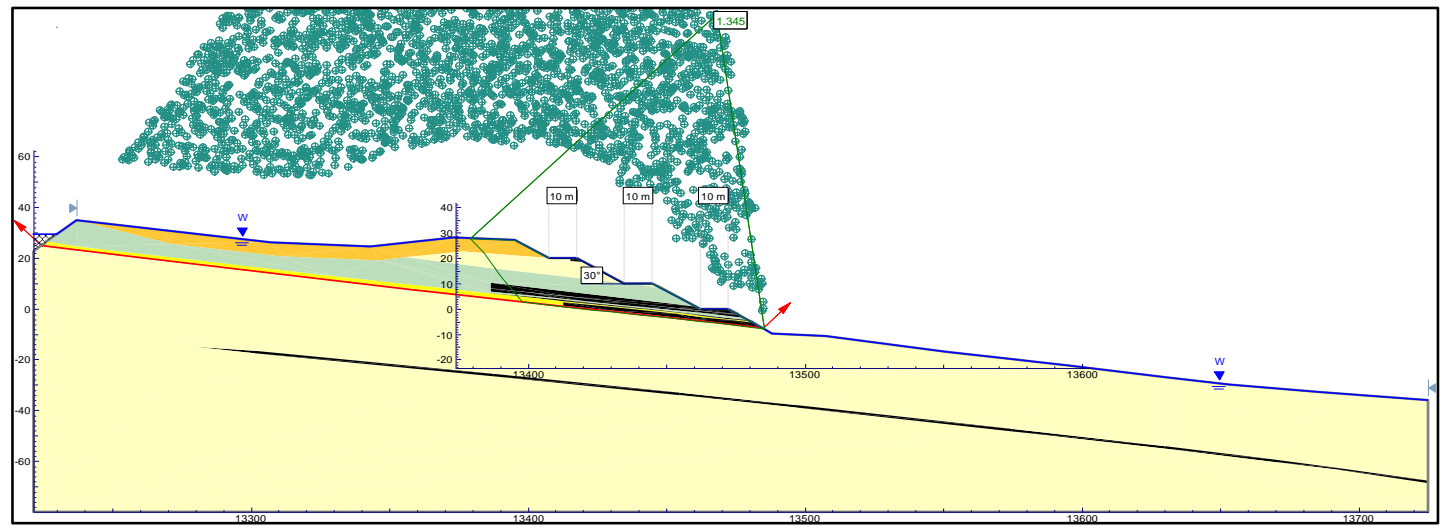

Gambar 4. Analisis Geoteknik Section - D Desain Lereng Undercut Sebelum Dibuat Buttress 
Section ini merupakan area paling kritis di lowwall Pit D2 karena mempunyai beda tinggi paling besar dan mempunyai kemiringan lereng > kemiringan lapisan (bedding undercut). Hasil analisa menunjukkan area ini mempunyai $\mathrm{FK}<1,300$ atau tidak aman dan berpotensi longsor.

Perlu dilakukannya pembentukan buttress atau counterweight dengan timbunan material OB keras yang membentuk desain In Pit Dump, hal ini digunakan untuk perkuatan pada kaki lereng dan menjaga kestabilan overall slope lereng lowwall Pit D2, dari sisi perencanaan tambang Pit D2 pada tahun 2019 juga menjadi opportunity volume disposal dengan jarak dekat.(Gambar 5)

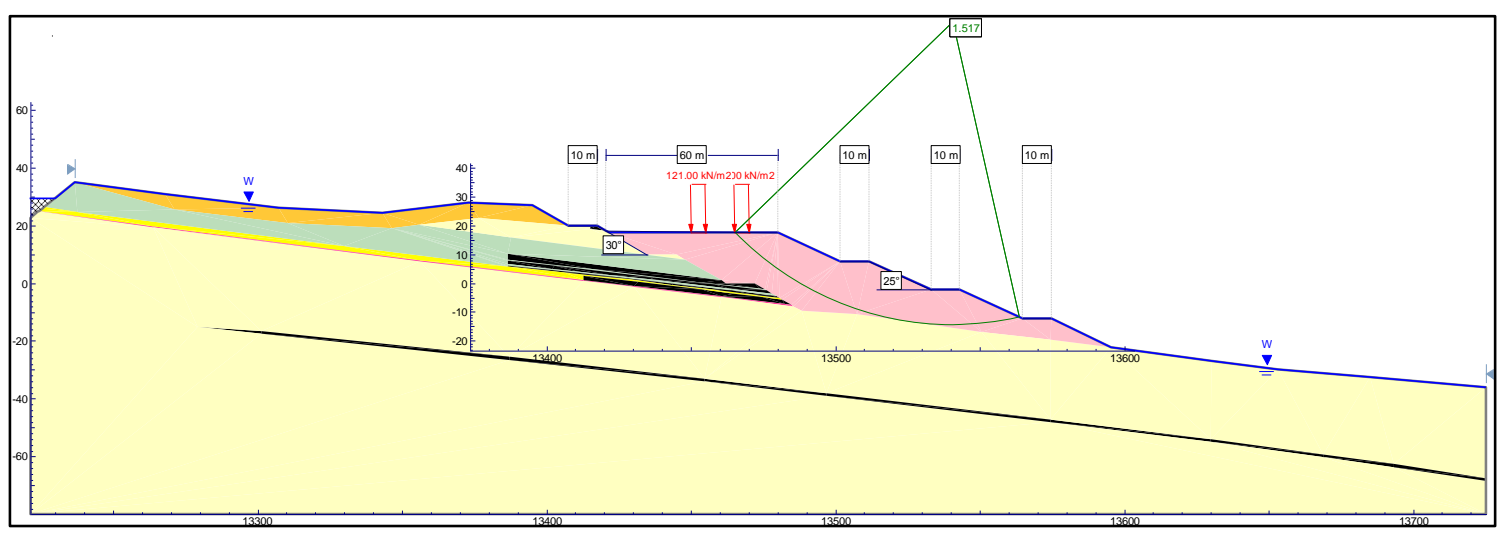

Gambar 5. Analisis Geoteknik Section - D Desain Lereng Undercut Setelah Dibuat Buttress

Pada akhirnya mine planning dan geotech engineer PT Berau Coal membuat desain besaran dari disposal IPD D2 yang menjadi keuntungan bagi volume disposal, short distance, dan juga pencegahan dari bahaya longsoran geoteknik diakibatkan desain undercut. (Gambar 6\&7)

- Analisis Timbunan Sidewall (IPD)

Analisis desain timbunan sidewall diwakili oleh section A-A'. Dimana pada section AA' kondisi FK > 1,3 dan sudah sesuai dengan standar aman geoteknik PT Berau Coal, dimana terdapat mine road pada elevasi +20 dan dibuatnya intermediate bench disetiap $30 \mathrm{~m}$ beda tinggi timbunan disposal.

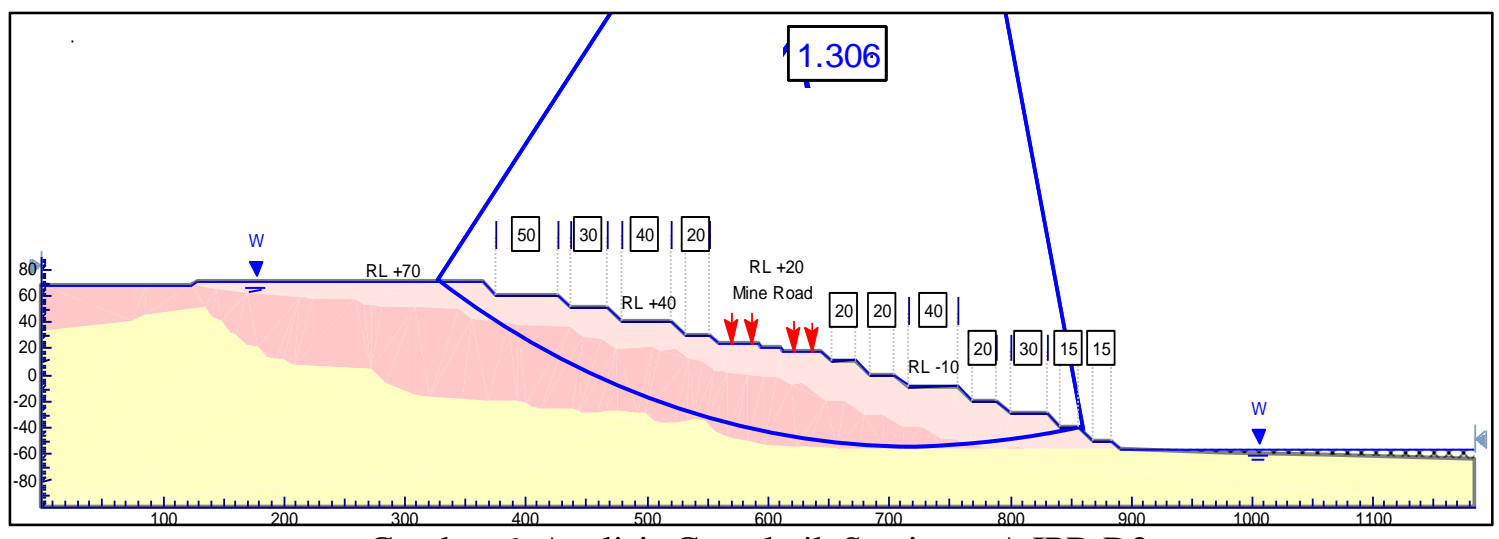

Gambar 6. Analisis Geoteknik Section - A IPD D2.

- Analisis Timbunan Lowwall (IPD)

Analisis desain timbunan low wall diwakili oleh section B-B' dan C-C'. Pada section ini kondisi FK > 1,3 dan sudah sesuai dengan standar aman geoteknik PT Berau Coal, dimana terdapat mine road pada elevasi 0 dan -30 dan dibuatnya intermediate bench disetiap 30m 


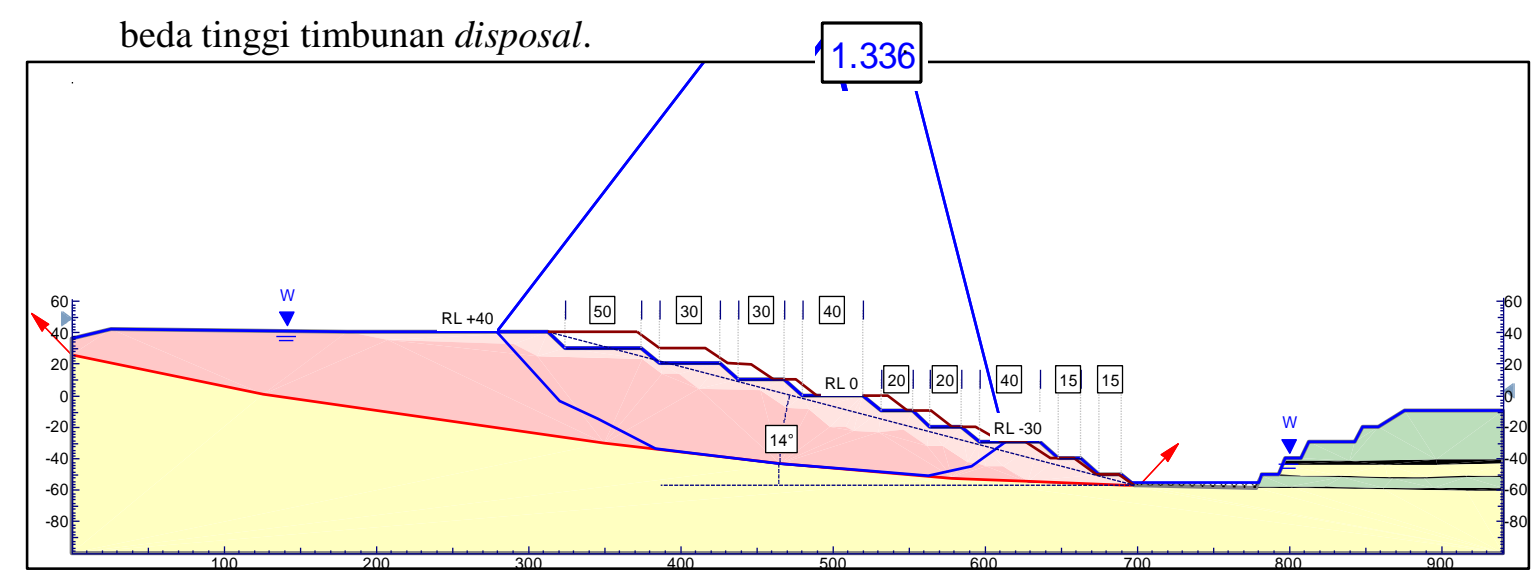

Gambar 7. Analisis Geoteknik Section - B IPD D2

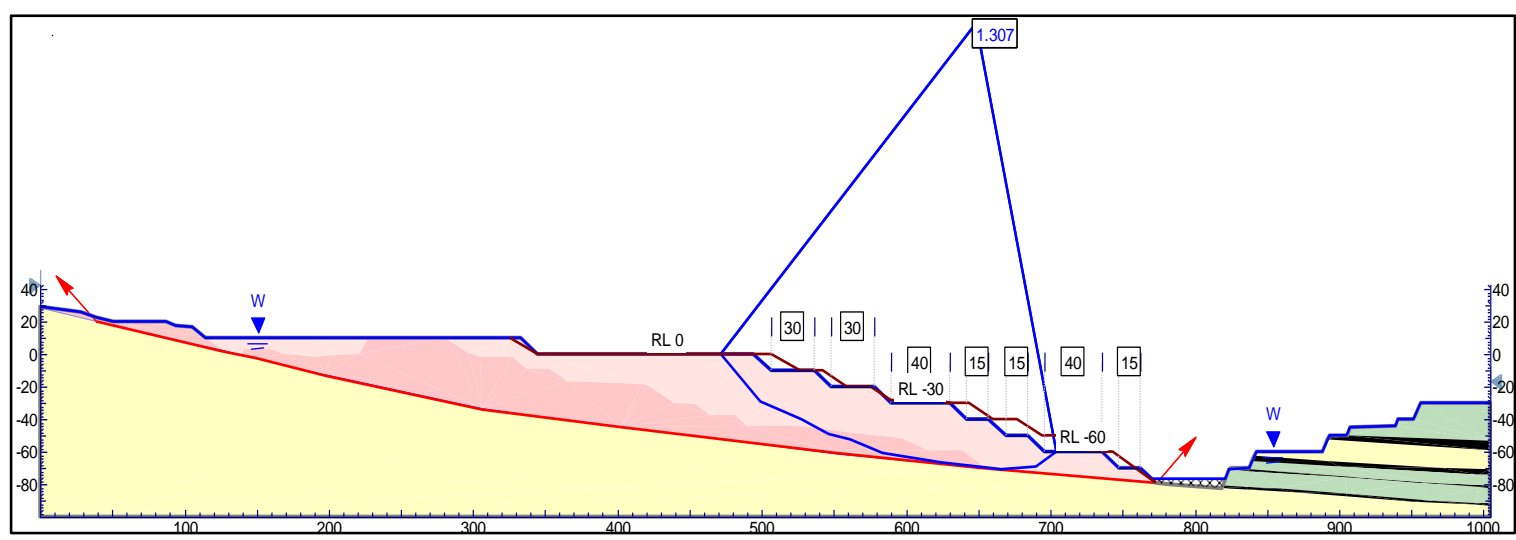

Gambar 8. Analisis Geoteknik Section - C IPD D2

\section{C.3 Distance dan Mitigasi Bahaya Geoteknik}

\section{C.3.1 Hasil Perhitungan Distance}

Simulasi distance berdasarkan kapasitas disposal IPD D2 maka didapatkan overall distance 2,4 $\mathrm{km}$.

Tabel 3. Perhitungan Over All Distance Pada Disposal Pit D2

\begin{tabular}{|c|c|c|c|c|c|c|c|c|c|c|c|c|c|}
\hline Description & Jan & Feb & Mar & Apr & May & Jun & Jul & Aug & Sep & Oct & Nov & Dec & Total \\
\hline OB Removal (BCM) & 962,064 & $1,128,091$ & 1,320,111 & $1,386,100$ & $1,375,673$ & $1,388,768$ & $1,552,516$ & $1,509,286$ & $1,513,025$ & $1,417,145$ & $1,300,170$ & $1,264,403$ & $16,117,353$ \\
\hline Distance $(\mathrm{m})$ & 2,264 & 2,402 & 2,414 & 2,436 & 2,418 & 2,418 & 2,418 & 2,416 & 2,418 & 2,428 & 2,425 & 2,430 & 2,412 \\
\hline Dump to OPD D2 & 328,596 & 384,724 & 445,537 & 469,910 & 475,788 & 471,613 & 528,510 & 519,030 & 513,371 & 474,839 & 441,046 & 429,060 & $5,482,024$ \\
\hline Distance $(\mathrm{m})$ & 2,225 & 2,345 & 2,347 & 2,365 & 2,364 & 2,365 & 2,365 & 2,364 & 2,366 & 2,365 & 2,365 & 2,365 & 2,353 \\
\hline Dump to IPD D2 & 348,992 & 408,485 & 469,444 & 475,770 & 472,959 & 483,708 & 539,742 & 523,698 & 527,035 & 498,093 & 456,422 & 439,163 & $5,643,510$ \\
\hline Distan & 1.700 & 1,800 & 1.800 & 1831 & 1,831 & 1.831 & 1.831 & 1,831 & 1,831 & 1,800 & & & 1,810 \\
\hline Dump to IPD K & 284,476 & 334,882 & 405,131 & 440,420 & 426,926 & 433,447 & 484,264 & 466,559 & 472,619 & 444,214 & 402,702 & 396,180 & $4,991,819$ \\
\hline Distance $(\mathrm{m})$ & 3,000 & 3,200 & 3,200 & 3,166 & 3,130 & 3,130 & 3,130 & 3,130 & 3,130 & 3,200 & 3,200 & 3,200 & 3,153 \\
\hline
\end{tabular}

Salah satu cost penambangan yang cukup besar dalam penambangan adalah distance. Berdasarkan perhitungan cost struktur, setiap kenaikan $100 \mathrm{~m}$ akan menaikkan mining cost 0,71 Million USD. Sehingga diperlukan rencana yang matang terkait penempatan disposal untuk mereduce distance.

\section{C.3.2 Mitigasi Bahaya Geoteknik}

Mitigasi bahaya geoteknik dilakukan agar operasional tambang berjalan sesuai rencana, baik dari sisi cost penambangan maupun sisi safety operational sehingga target produksi yang direncanakan dapat tercapai. Adapun mitigasi bahaya geoteknik yang dilakukan yaitu :

- Dilakukan pembentukan disposal IPD D2 pada area lowwall dari sisi selatan hingga utara,

- Dilakukannya perlakuan khusus pada desain bedding undercut dengan membetuk landai overall slope landai menjadi $20^{\circ}$ dengan single slope $30^{\circ}$ dan lebar bench minimal $10 \mathrm{~m}$

- Front kerja aktif penambangan dengan kaki disposal memiliki jarak 1 1/2 kali tinggi 
intermediate bench untuk mengantisipasi adanya geotechnical failure yang tidak tergambar didalam kajian,

- Memastikan pembuatan bench disposal sesuai dengan rekomendasi Dept. G\&H dan tinggi maksimal timbunan $10 \mathrm{~m}$,

- Pengaturan kemiringan permukaan jenjang / berm setidaknya 2\% untuk meminimalkan potensi air menggenang dipermukaan,

- Dilarang freedump (tumpuk-tumpuk) dan dumping material lumpur/rawa/lunak pada IPD D2 agar buttress dapat terbuat kuat untuk menahan potensi longsoran bidang,

- Evaluasi dan revisi akan dilakukan jika terdapat perbedaan data yang signifikan antara kondisi aktual material di lapangan dengan model yang digunakan dalam analisis,

- Pengawas memastikan area kerja aman, terutama pada awal shift, setelah hujan dan setelah blasting (peledakan). Jika ditemukan kondisi tidak aman, segera hentikan pekerjaan, evakuasi manusia dan unit, untuk selanjutnya dilakukan perbaikan terlebih dahulu sebelum pekerjaan dilanjutkan kembali,

- Ketentuan lain terkait safety, tetap mengacu pada Prosedur \& Standard BeGems (SOP PT. Berau Coal) yang berlaku.

\section{KESIMPULAN}

Berdasarkan hasil analisis dapat disimpulkan sebagai berikut :

1. Adanya bedding under cut di sisi side wall utara Pit D2, sesuai analisa dilakukan pembentukan single slope $30^{\circ}$ dan over all slope $\leq 15^{\circ}$ sehingga didapatkan FK 1,3,

2. Pembuatan disposal IPD D2 pada sisi low wall sesuai dengan desain revisi yang telah dilakukan kajian geoteknik PT Berau Coal,

3. Kapasitas IPD D2 5 MBCM sesuai kajian geotek sehingga didapatkan short distance $1,8 \mathrm{Km}$ yang mereduce distance Pit D2 dan didapatkan over all distance Pit D2 2,4 Km,

4. Kajian Geoteknik IPD D2 didapatkan FK 1,3 dengan over all slope $\leq 15^{\circ}$,

5. Mitigasi bahaya geoteknik dilakukan dengan percepatan IPD D2 terutama di side wall utara Pit D2

\section{DAFTAR PUSTAKA}

Pramajana, Gede., Pandu Zea. (2019): Kajian Geoteknik Desain Annual Pit D2, PT. Berau Coal, tidak ditebitkan.

Golder Associate (2018): Stability Assessment Blok 1-4, submitted for PT. Berau Coal, tidak diterbitkan.

Pramajana, Gede (2019): Kajian Geoteknik Desain IPD D2, PT. Berau Coal, tidak ditebitkan.

Prabudi, Alex (2018): Prosedur Pembuatan Desain Disposal, PT. Berau Coal, tidak ditebitkan.

Umboro, Sindu (2018): Prosedur Pemantauan Kestabilan Lereng, PT. Berau Coal, tidak ditebitkan.

Prio, Anjas (2018): Standar Desain Disposal, PT. Berau Coal, tidak ditebitkan. 